\title{
Relações sociais e poder em um contexto grupal: reflexões a partir de uma atividade específica
}

\author{
Andréa Vieira Zanella \\ Kléber Prado Filho \\ Sandra Iris Sobrera Abella \\ Universidade Federal de Santa Catarina
}

\begin{abstract}
Resumo
Este trabalho analisa as relações sociais de sujeitos participantes de um programa de formação em serviço, envolvidos em uma atividade cuja tarefa consistia em retratar a instituição em que trabalhavam. A coordenação do processo foi assumida, após um certo período de indefinição, por uma das participantes de maneira democrática, com o consentimento dos demais; num segundo momento, compartilhou esse lugar social com outro colega, o qual havia disputado com ela anteriormente a coordenação. Tal atividade possibilitou visualizar a forma como assumiram diferentes lugares sociais e a intrincada trama de relações de poder que estabeleceram, sendo que a análise das relações estabelecidas permitiu constatar que quando o lugar máximo de poder foi assumido com clareza, o trabalho do grupo fluiu e foi desenvolvido com o envolvimento de todos.
\end{abstract}

Palavras-chave: Grupo, Relações sociais, Psicologia social.

\begin{abstract}
Social relations and power in a context of group: Reflections through a specific activity. This work analyses the social relations of the participants who took part in a program of manager formation at work. They had realized a task which consisted of describing the institution where they work. Firstly, one of the participants assumed the co-ordination of the process in a democratic way by common consent. Secondly, she shared those social place with other colleague, which had disputed with her foregoing the co-ordination. Such activity permitted to visualize the form as they assumed different social places and the complicated web of power relations, and it also permitted to verify that when the place of maximum power was assumed clearly, the work of the group was developed with the involvement of all.
\end{abstract}

Key words: Groups, Social relations, Social psychology.

$\mathrm{E}$ ste trabalho visa analisar uma atividade na qual os sujeitos, participantes de um programa de formação de gerentes em serviço (PFGS) ${ }^{1}$ organizaram-se livremente para a realização de uma tarefa coletiva. As características das relações entabuladas pelos sujeitos possibilitam refletir sobre os lugares sociais assumidos, as características das negociações estabelecidas e o uso que fizeram do poder nesse contexto.

Como material para análise utilizou-se o registro escrito pormenorizado do processo grupal; imagens em VHS do "produto final” e fotografias tanto do processo de organização e criação conjunta quanto do momento da apresentação aos demais participantes do PFGS.

O relato e análise desse processo são aqui apresentados, posto que as reflexões engendradas podem servir de referencial para discussões sobre a organização de ativida- des em grupo em contextos de formação em serviço que tenham como preocupação ou diretriz a re-significação de lugares sociais e a reflexão sobre poder e ambiência democrática.

A questão que se apresenta e nos interessa discutir aqui refere-se, assim, à possibilidade de re-significação dos lugares sociais por sujeitos que convivem em seu cotidiano de trabalho com relações hierarquizadas nas quais as posições de poder são claramente definidas. Como se relacionam em um contexto de formação em serviço, onde aparentemente as diferenças hierárquicas institucionais não balizam as trocas com os colegas? Sendo solicitados a cumprirem determinada tarefa, como se organizam? Reproduzem as relações de poder características do contexto de trabalho? São capazes de resignificar lugares sociais institucionalizados? Essas questões nortearam as reflexões que são aqui apresentadas. 


\section{Relações sociais e poder: breves considerações teóricas}

A análise da atividade aqui apresentada foi desenvolvida tendo como base os pressupostos teóricos de autores de orientação crítica - Lane (1985); Carlos (1998); Tschiedel (1998); Góes (2000); Foucault (1987); Zanella e Sobrera Abella (2000); Zanella e Pereira (2001) - segundo os quais é possível afirmar que o sujeito se constitui nas relações sociais, sendo compreendido como "indivíduo concreto, mediado pelo social, indivíduo determinado histórica e socialmente, jamais podendo ser compreendido independentemente de suas relações e vínculos” (Neves, 1997, p. 7).

Assim, parte-se da compreensão do indivíduo em sua dupla dimensão, tanto ativa (sujeito) quanto passiva (sujeitado), na qual é produzido pelo meio social em que se insere sendo, no entanto, também capaz de transformá-lo. Portanto, é constituído/constitui-se no contexto das relações sociais, onde se apropria dos conhecimentos e técnicas da sociedade em meio aos grupos dos quais participa, ocupando diferentes lugares sociais.

Segundo Nuernberg (1999), o lugar social consiste na posição simbólica assumida pelo sujeito no grupo, a qual se, por um lado, precede o sujeito por basear-se em fatores históricos e culturais pré-determinados, por outro está continuamente sendo re-construída pelos sujeitos em relação. Sendo assim, o significado de lugar social remete necessariamente tanto à sua história para uma determinada cultura quanto aos novos sentidos que os sujeitos em relação a este lugar imprimem.

Demarca-se assim o fato de que as relações sociais são mediadas pelos significados historicamente produzidos para as posições ali assumidas, marcando os discursos dos sujeitos e a forma como são escutados e atendidos pela audiência. Em outras palavras,

...sempre falamos a partir de uma posição enunciativa determinada: de aluno, de professor, de homem, de mulher, de quem ocupa um cargo importante ou não, ou tem a formação acadêmica em alguma área do conhecimento e é reconhecido enquanto tal. Face a isso, fica claro que tais lugares sociais são constitutivos das significações em trânsito nas relações sociais... (p. 22).

Considerando que o sujeito se relaciona com os outros a partir do lugar social que ocupa, as relações entre as pessoas são aqui consideradas como relações de poder (Ortiz, 1983). Desse modo, compreende-se o poder como relacional, na medida em que se manifesta nas relações entre as pessoas, decorrendo mais precisamente da assimetria que as caracteriza. Assim, percebe-se que os relacionamentos não são necessariamente harmoniosos, apoiadores, concordantes; muitas vezes são permeados por conflitos, desencontros e desacordos (Smolka, Góes \& Pino, 1998).

De acordo com a perspectiva de Foucault (1987), o poder pode ser descrito a partir de algumas características: não se limita a aspectos institucionais e organizacionais e a formas econômicas, relações de classe, status, prestígio ou desempenho de papéis sociais; ele está presente em todas as rela- ções, na rua, na família, nas relações afetivas, de amizade etc. O poder também não se restringe a suas formas repressivas, anulando e destruindo o outro, pois em sua concepção "positiva” o poder é produtivo.

Além dessas características, destaca-se que o poder não é algo que se adquira ou se detenha, pois, não consistindo em propriedade ou mercadoria, circula na rede social, sendo da ordem das práticas; o poder vem de todos os pontos da rede social - não há uma fonte localizada onde ele se concentre e de onde emane. Desse modo, o poder deve ser pensado não nas grandes formas macro-políticas do Estado e da sociedade, mas em sua capilaridade e na multiplicidade de suas práticas, enfim, em seu movimento (Zanella, Prado Filho \& Sobrera Abella, no prelo).

Segundo Bourdieu (1989), o poder simbólico consiste em um poder exercido através do discurso, reconhecido pelos demais e legitimado devido à posição social de quem o profere. No entanto, somente recebe prestígio ou poder simbólico quem detém capital simbólico, ou é capaz de transformar alguma espécie de capital, como por exemplo, capital econômico, cultural ou social, em capital simbólico.

Ainda segundo Bourdieu, as lutas simbólicas estão sempre presentes no cotidiano, dissimuladas, entre os que têm interesse em manter as objetivações/representações oficiais (os dominantes) e os que pretendem transformá-los (os dominados). Assim, a partir do momento em que alguém ou um grupo é reconhecido pelos demais como detentor de alguma espécie de capital, possui, conseqüentemente, poder simbólico, exercido por meio do discurso, manipulado conforme os interesses de quem detém tal poder (Bourdieu, 1989).

Em conseqüência, as relações de poder tornam-se cada vez mais dissimuladas, ambíguas e abstratas. O poder já não é mais necessariamente atribuído a uma pessoa ou a grupos de pessoas; é considerado como algo que aparece dissimulado, não se sabe ao certo de onde vem, é a "mão invisível do poder” que na verdade está em todo lugar: na distribuição do espaço, na distribuição e produção do saber e das normas e no próprio funcionamento da organização. “A 'mão invisível', tão importante para os economistas liberais, está mais oculta do que nunca e mais operante no sentido da submissão do conjunto do sistema aos objetivos de lucro, expansão e dominação” (Pagès, Bonetti, Gaulejac \& Descendre, 1987, p. 225).

\section{Sobre os sujeitos e a proposta}

O processo aqui analisado teve como foco um grupo de 20 servidores públicos federais de um órgão da administração direta, participantes do Programa de Formação de Gerentes em Serviço (PFGS), promovido pela instituição na qual trabalhavam. O referido programa foi elaborado em resposta à demanda de muitos funcionários que identificavam problemas gerenciais, os quais reduziam a eficácia do trabalho realizado.

Tal programa atendia, naquele momento ${ }^{2}$, a 160 servidores organizados em 8 turmas de 20 participantes cada, com duração de 2 semanas, totalizando 80 horas de curso. Cada turma era composta por servidores oriundos de diferentes 
cidades brasileiras e que ocupavam diferentes cargos na hierarquia da instituição, desde altos postos, até com o mínimo poder de decisão.

Considerando que um dos objetivos do programa era a integração dos servidores e o reconhecimento de si e dos outros enquanto capazes de imprimirem mudanças no contexto de trabalho, a separação das turmas poderia significar um entrave a esse propósito. Para evitar essa situação, foi proposta uma atividade que visava superar essa separação e possibilitar a todos que pudessem se reconhecer enquanto funcionários da mesma instituição ${ }^{3}$.

A respeito da atividade, a partir dos resultados positivos obtidos com participantes anteriores do programa, a coordenação geral propôs que, no terceiro dia do evento, cada turma apresentasse às demais o retrato da instituição em que trabalhavam ou como gostariam que ela fosse. Para tanto, a única instrução dada foi a de que fariam essa apresentação e lhes seria proporcionado algum tempo para se prepararem ${ }^{4}$.

O grupo cuja atividade será aqui analisada foi constituído por participantes com características variadas: 65\% homens e 35\% mulheres; casados (80\%); com tempo de serviço na instituição igual ou superior a 15 anos (45\%) ou de 0 a 7 anos (40\%); com formação universitária e proveniente de áreas distintas do conhecimento (95\%); ingressos na instituição através de concurso de nível superior (80\%), sendo que os demais eram técnicos (20\%); não ocupavam cargo de chefia (75\%); quanto às regiões de onde provinham, a maioria estava concentrada nas regiões sul (20\%), centro-oeste (25\%) e sudeste (30\%); e 60\% dos participantes trabalhava em órgãos locais.

Vale destacar que essas características permitiram que diferentes lugares sociais se estabelecessem na instituição a despeito das funções desempenhadas, como por exemplo, na valorização dos funcionários que ingressaram na empresa através de concurso de nível superior. A diferença salarial entre as duas condições de emprego (superior e técnico) e o fato de que, uma vez ingresso na organização, não havia possibilidade de ascensão, a não ser mediante a realização de um novo concurso público, balizavam as relações sociais no contexto institucional. Também existiam distinções com relação ao órgão em que trabalhavam, pois os órgãos locais ocupavam um lugar inferior na escala hierárquica, enquanto o órgão central detinha maior poder decisório na instituição ${ }^{5}$.

No decorrer da atividade que será aqui analisada, este mapeamento das condições dos sujeitos anteriores à participação no PFGS, ainda que sucinto, permite observar até que ponto as posições ocupadas na instituição influenciaram as relações entre os participantes. A seguir, será apresentado um relato do processo grupal a partir do material coletado na realização da atividade, o qual consistiu predominantemente, no registro escrito da observação.

\section{O processo do grupo}

No dia da apresentação, Eliana, uma das integrantes do grupo, falou de sua preocupação quanto ao que seria feito naquele dia e solicitou que a consultora responsável pela socialização dos conhecimentos junto à sua turma cedesse tempo para que pudessem se preparar. Como a apresentação estava prevista para o final da tarde, foi combinado que teriam tempo para se dedicarem a isso ao final das atividades da manhã.

Consonante com as falas de outros participantes, essa atitude de Eliana, mais que iniciativa individual, expressava a preocupação de todos em realizar a atividade proposta da melhor forma possível, reivindicando, para tanto, um tempo maior que o anteriormente previsto. Vale destacar que as observações da conduta dos participantes no decorrer do programa de formação revelavam que Eliana era uma pessoa que, até então, não tinha tido grande expressão junto ao grupo. Esse lugar se revelava igualmente, pode-se dizer, na instituição em que trabalhava: funcionária de nível técnico, ela ocupava hierarquicamente a escala rasa na estrutura de cargos.

A partir do momento em que foram liberados para se prepararem, a discussão sobre "o que” e “como” fazer começou com as sugestões espontâneas dos participantes. Fábio, que estava havia apenas 8 meses na instituição, sugeriu que se representasse uma reunião de superintendentes, consistindo a tarefa em retratar o cotidiano. É interessante que a primeira proposta apresentada foi a representação da mais alta instância de poder, pois, de certa forma, caracterizava a instituição na qual se inseriam: hierarquizada, formalizada, oficializada, com o poder claramente localizado e demarcado.

Maria foi a próxima participante a sugerir uma temática a ser apresentada: como a instituição avalia os funcionários. Essa sugestão demonstrou sua perspectiva em relação ao poder: ela queria que se desse visibilidade à maneira como eles eram vistos pela instituição, ou seja, que relação era essa que a instituição estabelecia com seus funcionários.

Hélio tentou organizar o grupo, delegando a função de coordenação para Eliana, sendo que o seu propósito era de que ela de certa forma direcionasse o trabalho e decidisse o que fazer. Eliana assumiu a coordenação, porém contrariando de certa forma a proposta de Hélio: logo de início, após as duas sugestões descritas, propôs um brainstorm e perguntou quem se disporia a anotar as idéias que surgissem, sendo que Maria se voluntariou para a função. Em meio à 'chuva de idéias’, Plínio sugeriu um cinema mudo em alta velocidade, propondo que fosse escolhido primeiro a forma de apresentação. Assim, com sua sugestão, opôs-se à proposta dos demais colegas, que era a de escolher primeiramente a temática para só depois decidir qual seria a forma de apresentação mais adequada.

As respostas foram categorizadas de acordo com as temáticas sugeridas, apresentando um quadro dos principais problemas enfrentados por estes servidores públicos: as condições de trabalho; as relações entre as diferentes unidades na instituição; as relações nas unidades internas; a situação da instituição perante o Estado e a sociedade; e a relação entre servidores e "cúpula" - referindo-se essa expressão aos funcionários que ocupavam as mais altas posições hierárquicas na instituição. Foram, portanto, cinco propostas que enfocavam relações internas às unidades da instituição, relações entre unidades e relações da instituição com outros segmentos da sociedade. 
Nesse momento, Eliana retomou a coordenação perguntando: “qual é o nosso objetivo?” Incitou assim o grupo a definir o que queria, sendo importante ressaltar que o objetivo do exercício não consistia necessariamente em uma crítica, tratava-se de um retrato; no entanto, ao assumir ainda que de forma tímida a coordenação do processo, direcionou as discussões apontando para o grupo que o retrato a ser feito tinha de ser necessariamente um retrato crítico.

Importante destacar que até esse momento Eliana assumia o lugar social de coordenadora do processo em alguns momentos, sendo que para o grupo como um todo essa posição não parecia clara. Essa afirmação sustenta-se na dinâmica do processo, pois as sugestões eram apresentadas concomitantemente, sem uma clareza de objetivos e com disputas pelo direito à voz e vez. Essa confusão continuou na seqüência dos acontecimentos.

Novamente Plínio insistiu em sua posição, propondo que fizessem várias paródias e fosse escolhida a melhor. Maria e Pedro apresentaram novas propostas de temas e, ao serem contestadas por Plínio, provocaram reação de Maria, que se contrapôs afirmando: "mas isso seria individual, e a proposta é de produção coletiva”. Maria defendeu, assim, a idéia de que o que tinha de ser escolhido primeiro era o tema, apoiando a proposta de Eliana. Interessante essa aproximação entre Maria, Pedro e Eliana, porque consistiu em uma aliança de esferas completamente distintas da realidade institucional: Maria era sindicalista, Pedro ocupava um alto cargo na instituição e Eliana, o baixo escalão. Ao se unirem, eles, de uma certa forma, romperam com as delimitações da instituição, que os colocava em lugares sociais opostos no cotidiano: Maria representava os funcionários, enquanto Pedro representava a cúpula institucional ${ }^{6}$ e Eliana expressava o cotidiano de vários trabalhadores que de certa forma estavam excluídos do exercício do poder institucional.

Eliana posicionou-se diante do impasse afirmando que a escolha da música dependeria do tema. Nesse momento ela se levantou para coordenar a discussão, porque ainda que a estivesse exercendo, o fazia parcialmente, de forma não oficial. A seguir Plínio voltou a insistir em sua proposta, sugerindo um brainstorm, com cada um escrevendo uma letra de música. Outros dois participantes, Eduardo e Marcos, chamaram-lhe a atenção, pontuando que ele estava atropelando o processo: "Plínio, você já definiu que é paródia e a gente nem definiu o que vai ser ainda!”. Reafirmaram assim a proposta de que a decisão deveria ser coletiva. Eduardo, a seguir, chamou a atenção do grupo para o objetivo, dizendo que este estava gastando mais tempo discutindo do que fazendo.

Nesse momento, Eliana conversou privadamente com a consultora solicitando que esta coordenasse o processo. Apesar da angústia de Eliana, a consultora não interferiu e disse para ela assumir esse lugar, pois o que parecia estar faltando era assumir de fato a coordenação que estava exercendo de forma tímida. Após a conversa, a postura de Eliana mudou: voltou-se para o grupo, foi para frente e perguntou aos colegas se eles concordavam que alguém assumisse a coordenação do processo e se ela poderia assumir essa posi- ção. Todos aquiesceram. Eliana assumiu com legitimidade esse lugar dizendo: "Todos os colegas têm idéias brilhantes. Vamos ouvir a idéia de todos”. Depois disso, o trabalho do grupo fluiu, ou seja, essa demarcação clara do lugar central de poder após a definição de quem coordenaria os trabalhos tirou o grupo de um certo impasse.

Após todos falarem, Eliana sintetizou afirmando: "Nós temos esses temas e alguns englobam outros”. Após essa análise, solicitou ao grupo que identificasse o que havia em comum entre esses temas aparentemente independentes. Pedro propôs uma votação e, para tanto, solicitou a Júlio que explicitasse a sua proposta e pensasse como poderia ser apresentada. Solicitou ainda que todos escutassem, porque lhe parecia que a proposta de Júlio era um pouco mais ampla que as demais: se essas remetiam a setores específicos, a proposta dele enfocava a instituição como um todo. Júlio explicou e Otávio perguntou como é que isso poderia ser feito. Júlio respondeu que poderia ser paródia, e Eliana complementou afirmando que poderia ser dramatização, música, paródia.

O tema foi votado e a proposta de Júlio, da “quebradeira”, ganhou por ampla maioria. O grupo assim optou por uma temática que dizia da vida de todos e da instituição de um modo geral. Mauro chamou a atenção para que passassem para a segunda etapa - a escolha da forma de apresentação. Eliana questionou a proposta do jogral, ao que Hélio respondeu: “Você não sabe, mas quem sugeriu sabe!”. Defendeu assim que o jogral fosse mantido na relação de propostas.

Nesse episódio constatou-se que, quando Eliana se posicionou perante o grupo manifestando sua opinião, saindo assim do lugar de coordenadora, um participante chamou a sua atenção para que reassumisse o seu lugar perante o grupo e garantisse a todos o direito à palavra, o que significava que todas as sugestões deveriam ser mantidas.

Na continuidade, Júlio sugeriu uma votação para definirem a forma de apresentação da temática escolhida. Hélio propôs que todas as propostas fossem contempladas, à qual Marcos se opôs: "mas essa proposta não existe". Sua intervenção desencadeou uma nova discussão. Após alguns minutos, todos chegaram ao consenso de que poderiam utilizar vários recursos. Para finalizar esse momento dos trabalhos, Eliana passou como tarefa para a hora do almoço que pensassem em como aquele tema poderia ser desenvolvido.

Durante o período da tarde, eles concretizaram o objetivo a que tinham se proposto. Nessa nova etapa, o grupo trabalhou completamente integrado, criando, inventando. Apesar de no período da manhã Plínio e Eliana terem disputado o comando, nesse momento, de forma não deliberada, os dois assumiram a coordenação da atividade. Plínio se dirigiu para frente do grupo posicionando-se ao lado de Eliana e contribuiu com a organização das discussões e encaminhamento do trabalho.

Coletivamente construíram o enredo e, para sua apresentação, o grupo foi subdividido e as necessidades arroladas. Surgiram assim diversos subgrupos: da música, da infra-estrutura, um que iria detalhar o enredo, outro responsável pela caracterização dos personagens e providenciar os materiais necessários. Praticamente todos assumiram alguma tarefa e 
rapidamente se mobilizaram para dar conta da mesma. Mariana, que estava dispersa, aos poucos se integrou e Hélio, que também estava disperso, saiu da sala e voltou com um violão, passando a participar quando o grupo da música o chamou.

O produto final foi uma encenação musicada, através de uma paródia com conteúdo extremamente crítico feita a partir de uma música muito conhecida do público brasileiro, utilizando para tanto vários recursos e formas de expressão: canto, dramatização e sinalização gráfica.

\section{Reflexões sobre o processo do grupo}

A concepção na qual o presente trabalho se fundamenta, segundo as referências utilizadas, é a de poder disseminado de modo sutil nas relações cotidianas, o que vai ao encontro de reflexões propostas por Bourdieu (1989), Foucault (1987) e Ortiz (1983). Nesse sentido, diversos aspectos puderam ser percebidos na atividade analisada: os lugares sociais assumidos pelos sujeitos influenciaram as relações com os demais participantes, sendo que em alguns momentos o grupo reproduziu a estrutura da/na instituição no contexto grupal, porém não reproduzindo propriamente os modos de relação habituais, cotidianos e, em outros momentos, conseguiu romper com a realidade institucional. Assim, pode-se afirmar que o PFGS se constituiu, para o grupo em questão, em um espaço que viabilizou algumas situações que, na instituição, em razão da formalidade e rigidez da estrutura hierárquica estabelecida, não seriam possíveis.

De modo geral, conforme foi possível constatar no relato apresentado, a diferença entre as posições ocupadas na instituição não influenciou as relações sociais estabelecidas naquele contexto, ou seja, os participantes não se relacionaram a partir dos cargos exercidos. Porém, em três situações foi possível perceber que os cargos ocupados na instituição influenciaram, de certa forma, as relações entre os participantes: Hélio (funcionário de nível superior), delegou a função de coordenadora para Eliana (funcionária de nível técnico, não-chefe e ocupante de cargo de baixo poder decisório na organização); Plínio (que ocupava cargo de chefia) disputou o poder com Eliana e depois os dois coordenaram a atividade conjuntamente; Maria (sindicalista, de nível superior) e Pedro (chefe, de nível superior) se aliaram a Eliana, frente ao confronto com Plínio, formando uma aliança para apoiar a posição defendida por esta, a qual vinha ao encontro das opiniões da maioria.

As relações sociais que caracterizavam o cotidiano do universo de trabalho desses sujeitos, estabelecidas a partir da desigualdade existente na estrutura hierárquica e conseqüente distribuição desigual de capital em suas diversas formas, caracterizou-se, no contexto do PFGS, em diversos momentos como desarmônicas - nos confrontos de opiniões, conflitos, discordâncias - e, em outros momentos, como harmônicas - nos casos de alianças, concordâncias. A síntese desses encontros/confrontos, por sua vez, possibilitou aos sujeitos tomarem decisões e criarem coletivamente.

A posição de coordenação esteve aberta, ou seja, não esteve demarcada por um razoável período de tempo, sendo que durante este alguns participantes competiram por posições, não chegando a um consenso. No momento em que o lugar de coordenação do processo foi formalizado, ou seja, quando se demarcou que a partir de determinado momento Eliana seria a coordenadora e todos a reconheceram como tal, o trabalho fluiu de maneira mais cooperativa e menos competitiva. A respeito disso pode-se observar que, apesar das possibilidades presentes de se quebrar os modos habituais de organização, em alguns momentos o grupo confirmou a necessidade de tutela, característica do funcionamento institucional.

A forma como Eliana assumiu a coordenação merece destaque, pois exercitou o poder democraticamente, perguntando para o grupo se ele a aceitaria como coordenadora, usando assim um poder concedido pelos colegas e referenciado por estes. Essa dinâmica caracterizou a forma como eles se sujeitaram ao poder e necessitaram do poder com lugar marcado, definido, mesmo que fosse um poder democrático por um deles exercido.

Pode-se entender que a postura de Plínio no grupo, inicialmente competitiva e individualista, impedia o trabalho de fluir. Quando se formalizou a coordenação, a postura mudou completamente: submeteu-se à decisão da maioria e passou a colaborar com o processo.

Considerando o pressuposto de que a resistência ocorre quando o poder está claro, demarcado (Foucault, 1987), é possível afirmar que os componentes do grupo resistiram justamente quando não havia uma definição clara com relação aos lugares de quem mandava e de quem obedecia. Nesse sentido, o modo de ação de Plínio no grupo durante essa atividade pode ser entendido como uma resistência clara ao grupo de modo geral, porque ele confrontava tudo o que era coletivo. Por outro lado, pode-se compreender seu modo de ação não como uma resistência ao poder em si, mas como uma competição pelo lugar de comando, consistindo em uma disputa pela voz principal, ou seja, pelo lugar de responsável pela condução do processo.

É interessante perceber em que momento Eliana e Plínio coligaram. Plínio era o defensor de se definir primeiramente a forma; em conseqüência, quando era para definir tanto o conteúdo como a forma, a coordenação correu por conta de Eliana. Quando, porém, chegou o momento da forma ser executada, Plínio acabou coordenando o grupo conjuntamente com Eliana.

Interessante também destacar que a forma de organização que lhes permitiu realizar a atividade eficientemente foi a divisão de tarefas. Esta, porém, foi balizada pelo objetivo final e caracterizou-se por abrir espaço para as pessoas criarem.

\section{Considerações Finais}

Considerando que a tarefa, na atividade analisada, teve uma função mediadora na medida em que, por seu intermédio, os integrantes se organizaram, se relacionaram e trabalharam, foi possível observar que esse grupo centrou-se nos objetivos propostos: consideraram metas, tempo para realização 
da atividade e o desempenho esperado de cada um como eixos norteadores das ações no grupo. É possível afirmar também que os integrantes desse grupo, funcionando como um coletivo, foram, do ponto de vista dos resultados, eficientes e, do ponto de vista do processo, politicamente competentes, sujeitando-se ao coletivo. No entanto, cabe destacar que atravessou, nesta atividade, uma questão ideológica central ao funcionamento e ao sucesso do grupo, que foi a noção de democracia como diretriz para a tomada de decisões.

O resultado político desses sujeitos foi, portanto, democrático, pluralista e coerente com o processo vivido, permitindo o movimento e a manifestação de todos. Nesse sentido, o exercício proposto foi importante na medida em que permitiu aos sujeitos ocuparem lugares sociais de comando sem a tutela das posições que ocupavam no contexto de trabalho. A forma como o fizeram, a partir de uma escolha conjunta, em que lideranças emergiram, possibilitou re-significarem, ainda que em um contexto fictício, o lugar que ocupavam na esfera institucional. Ali efetivamente se apresentaram como sujeitos capazes de produzir história, ainda que suas ações tenham sido balizadas pela história da qual participavam e que os produzia.

\section{Referências}

Bourdieu, P. (1989). O poder simbólico. Lisboa: DIFEL.

Carlos, S. A. (1998). O processo grupal. In M. G. C. Jacques, M. N. Strey, N. M. G. Bernardes, P. A. Guareschi, S. A. Carlos \& T. M. G. Fonseca (Orgs.), Psicologia social contemporânea (pp. 199-206). Petrópolis: Vozes.

Foucault, M. (1987). Vigiar e punir: nascimento da prisão (5ํㅡㄹ. ed.). Petrópolis: Vozes.
Góes, M. C. R. (2000). A abordagem microgenética na matriz histórico-cultural: uma perspectiva para o estudo da constituição da subjetividade. Caderno CEDES, 50, 9-25.

Lane, S. T. M. (1985). O processo grupal. In S. T. M. Lane \& W. Codo (Orgs.), Psicologia social: o homem em movimento ( $2^{\underline{a}}$ ed., pp. 78-98). São Paulo: Brasiliense.

Neves, W. M. J. (1997). As formas de significação como mediação da consciência: um estudo sobre o movimento da consciência de um grupo de professores. Tese de doutorado não-publicada. Pontifícia Universidade Católica de São Paulo, São Paulo.

Nuernberg, A. H. (1999). Investigando a significação de lugares sociais de professora e alunos no contexto de sala de aula. Dissertação de mestrado não-publicada. Universidade Federal de Santa Catarina, Florianópolis.

Ortiz, R. (1983). A procura de uma sociologia da prática. In R. Ortiz (Org.), Pierre Bourdieu: Sociologia (pp. 7-36). São Paulo: Ática.

Pagès, M., Bonetti, M., Gaulejac, V., \& Descendre, D. (1987). O poder das organizações: a dominação das multinacionais sobre os indivíduos. São Paulo: Atlas.

Smolka, A. L. B., Góes, M. C. R., \& Pino, A. (1998). A constituição do sujeito: uma questão recorrente? In J. V. Wertsch, P. del Río \& A. Alvarez (Orgs.), Estudos socioculturais da mente (pp. 218-238). Porto Alegre: Artmed.

Tschiedel, R. G. (1998). O grupo como espaço de construção da heterogeneidade à heterogênese. Dissertação de mestrado não-publicada, Pontifícia Universidade Católica do Rio Grande do Sul, Porto Alegre.

Zanella, A. V., \& Sobrera Abella, S. I. (2000). Grupo, cultura e constituição do sujeito: o movimento dos sujeitos no contexto grupal. Relatório final de pesquisa não-publicado. Programa PIBIC/CNPq - BIP/UFSC. Universidade Federal de Santa Catarina, Florianópolis.

Zanella, A. V., \& Pereira, R. S. (2001). Constituir-se enquanto grupo: a ação de sujeitos na produção do coletivo. Estudos de Psicologia, 6, 105-114.

Zanella, A. V., Prado Filho, K. \& Sobrera Abella, S. I. (no prelo). Significações acerca de poder em um grupo de formação de gerentes em serviço. Psicologia Argumento.

1 O nome do programa, tal como a sigla aqui apresentada e os nomes dos sujeitos, são fictícios.

2 O PFGS em questão pretendia atender a todos os servidores da instituição promotora, porém foi interrompido em meados de 1998. As análises aqui apresentadas aconteceram com a terceira turma de servidores que participaram do programa.

3 Esse momento foi observado como extremamente importante para o grupo em uma análise realizada em outro trabalho (Zanella \& Pereira, 2001). Constatou-se que essa atividade pode ser identificada como consolidadora do grupo, pois foi a partir dela que seus integrantes passaram a trabalhar coletivamente no decorrer do curso. Se, antes, havia um movimento nesse sentido, durante a atividade, os sujeitos estabeleceram alianças e administraram os conflitos resultantes das disputas pelo direito a voz e vez, bem como pela coordenação do processo, constituindo-se, propriamente, um coletivo.

4 Importante salientar que essa apresentação já estava prevista, portanto, no plano de atividades que foi entregue aos participantes no primeiro dia de curso.

5 Essa diferenciação, baseada na valorização de determinadas características e posições ocupadas na instituição, foi mapeada a partir de uma atividade realizada no primeiro dia do programa, sendo que as informações provieram dos próprios participantes.

6 Também é importante salientar que Plínio, o participante que estava propondo insistentemente a escolha da forma, também ocupava um alto posto na escala hierárquica da instituição.

7 Júlio sugeriu, como tema, a “quebradeira da instituição”, ou seja, a situação crítica, a questão do orçamento, dos recursos, a relação com os órgãos externos, tendo afirmado: “a instituição está sendo boicotada”. 
Andréa Vieira Zanella, doutora em Psicologia da Educação pela Pontifícia Universidade Católica de São Paulo, é professora do Departamento de Psicologia da Universidade Federal de Santa Catarina e bolsista de Produtividade em Pesquisa do CNPq.

Kléber Prado Filho, doutor em Sociologia pela Universidade de São Paulo, é professor do Departamento de Psicologia da Universidade Federal de Santa Catarina.

Sandra Iris Sobrera Abella é acadêmica do curso de Psicologia da Universidade Federal de Santa Catarina e bolsista de Iniciação Científica pelo programa PIBIC/CNPq - BIP/UFSC.

Endereço para correspondência: Universidade Federal de Santa Catarina, Centro de Filosofia e Ciências Humanas, Departamento de Psicologia, Campus Trindade, 88010-970, Florianópolis, SC. Fone/Fax: (48)331.9984.E-mail: azanella@cfh.ufsc.br 